\title{
Serum levels of vitamin D in patients with recurrent aphthous stomatitis
}

\author{
Masume Zakeri ${ }^{1, B, D-F}$, Hadi Parsian ${ }^{2, A, E}$, Ali Bijani ${ }^{3, C, E}$, Atena Shirzad ${ }^{4, A, D-F}$, Nahid Neamati ${ }^{2, B}$ \\ 1 Student Research Committee, School of Dentistry, Babol University of Medical Sciences, Iran \\ 2 Department of Clinical Biochemistry, School of Medicine, Babol University of Medical Sciences, Iran \\ ${ }^{3}$ Social Determinants of Health Research Center, Health Research Institute, Babol University of Medical Sciences, Iran \\ ${ }^{4}$ Oral Health Research Center, School of Dentistry, Babol University of Medical Sciences, Iran \\ A - research concept and design; $B$ - collection and/or assembly of data; $C$ - data analysis and interpretation; \\ $D$ - writing the article; $E$ - critical revision of the article; $F$ - final approval of the article
}

Address for correspondence

Atena Shirzad

E-mail: ats60dent@gmail.com

\section{Funding sources}

This research project was funded from the Research and Technology resources of Babol University of Medical Sciences, Iran.

\section{Conflict of interest}

None declared

Acknowledgements

The authors kindly appreciate the financial support provided by the Deputy Dean for Research and Technology at Babol University of Medical Sciences in Iran. This study is part of the dissertation by Masume Zakeri (code: 9706271).

Received on May 22, 2020

Reviewed on July 17,2020

Accepted on August 13, 2020

Published online on March 22, 2021

Cite as

Zakeri M, Parsian H, Bijani A, Shirzad A, Neamati N. Serum levels of vitamin $D$ in patients with recurrent aphthous stomatitis. Dent Med Probl. 2021;58(1):27-30. doi:10.17219/dmp/126360

DOI

$10.17219 / \mathrm{dmp} / 126360$

Copyright

○) 2021 by Wroclaw Medical University

This is an article distributed under the terms of the

Creative Commons Attribution 3.0 Unported License (CC BY 3.0)

(https://creativecommons.org/licenses/by/3.0/).

\begin{abstract}
Background. Recurrent aphthous stomatitis (RAS) is one of the most common recurrent ulcerations in the oral mucosa, the etiology of which has not been elucidated; the immune system dysfunction may play an important role in the pathogenesis of RAS. The anti-inflammatory and regulatory role of vitamin D in the functioning of the immune system is well-documented.

Objectives. This study aimed to evaluate and compare the serum levels of vitamin D between patients with RAS and healthy controls.

Material and methods. In this case-control study, 43 patients with minor RAS and 43 healthy controls were included. Two groups were matched in terms of age and sex. Blood samples were obtained from all participants. The serum levels of vitamin D were measured with the use of the enzyme-linked immunosorbent assay (ELLSA) in patient and control groups. The data was analyzed using the SPSS for Windows software, v. 17.0, with the independent samples $t$ test and the Mann-Whitney test. A $p$-value of $<0.05$ was considered statistically significant.

Results. The mean serum level of vitamin $D$ in the control group was significantly higher than that in the case group $(22.59 \pm 16.06 \mathrm{ng} / \mathrm{mL}$ vs $13.19 \pm 8.19 \mathrm{ng} / \mathrm{mL}$, respectively; $p=0.002)$.

Conclusions. The serum levels of vitamin D are lower in patients with RAS in comparison with healthy controls.
\end{abstract}

Key words: vitamin D, immune system, recurrent aphthous stomatitis 


\section{Introduction}

Recurrent aphthous stomatitis (RAS) is one of the most common recurrent ulcerations in the oral mucosa. It mostly occurs in societies with a high socioeconomic status and affects $5-25 \%$ of the population. ${ }^{1}$ The lesions are self-limiting. Pain and oral dysfunction are the most important complications of chronic inflammatory lesions. ${ }^{2}$

Recurrent aphthous stomatitis is classified into 3 clinical forms: minor; major; and herpetiform ulcerations, with the minor form being the most common. ${ }^{2}$ Multiple factors, including genetic and hematologic disorders, immunological deficiency, stress, and trauma, are known as predisposing for RAS. ${ }^{3,4}$ Many researchers have evaluated the role of the immune system dysfunction in aphthous stomatitis. According to their studies, at the early stages of RAS, CD4 ${ }^{+} \mathrm{T}$ lymphocytes are predominantly involved, and at the ulcerative stages $-\mathrm{CD}^{+} \mathrm{T}$ lymphocytes. ${ }^{5}$ An increase in Th1 pro-inflammatory cytokines and a decrease in Th2 anti-inflammatory cytokines in the pathogenesis of RAS are confirmed., ${ }^{6,7}$ Recent studies have shown the role of vitamin $\mathrm{D}$ in skeletal disorders, cardiovascular diseases, cancers, and autoimmune diseases, such as rheumatoid arthritis, systemic lupus erythematous and type 1 diabetes mellitus. ${ }^{8-10}$ The antiinflammatory and regulatory role of vitamin $\mathrm{D}$ in the functioning of the immune system is well-documented. ${ }^{9}$ Vitamin D receptor (VDR) is found in most cells of the immune system, including antigen-presenting cells (APCs). Serum 25(OH)D is considered the most accurate marker for vitamin $\mathrm{D}$ status. It is well known that the measurement of $25(\mathrm{OH}) \mathrm{D}$ levels is the best indicator of the vitamin D status in humans. ${ }^{10,11}$

$1,25(\mathrm{OH})$-vitamin D3 is the metabolically active form of vitamin $\mathrm{D}$ which inhibits the maturation of dendritic cells, and shifts the balance of the differentiation pathway from Th1 and Th17 into Th2 and regulatory $\mathrm{T}$ cells, respectively. The inflammatory response is increased by Th1 and decreased by Th2. Therefore, vitamin $\mathrm{D}$ modulates the immune system through reestablishing the balance between the immune system components. ${ }^{11-13}$

However, the role of vitamin $\mathrm{D}$ in the pathogenesis of RAS is not clear, and contradictory results have been reported. Öztekin and Öztekin showed a decreased serum level of vitamin D in patients with RAS, ${ }^{10}$ whereas Krawiecka et al. reported no significant difference between patients with RAS and healthy individuals in terms of serum vitamin D levels. ${ }^{7}$

\section{Objectives}

Therefore, the current study aimed to compare the serum levels of vitamin D in RAS patients and healthy individuals.

\section{Material and methods}

The participants in this case-control study were referred to the Department of Oral and Maxillofacial Medicine of the School of Dentistry at Babol University of Medical Sciences in Iran (Ethics committee code: IR.MUBABOL.HRI.REC.1397.204).

The sample size for each group $(n=43)$ was calculated with a $95 \%$ confidence level, a study power of $80 \%$, and by considering a 5-unit difference in the serum levels of vitamin $\mathrm{D}$ between the 2 groups.

Individuals with RAS, aged 15-40 years, were included in the case group. An aphthous ulcer was diagnosed based on the clinical manifestation ( 1 or 2 minor RAS ulcers, $<1 \mathrm{~cm}$ in diameter, located in the buccal or labial mucosa) and at least 3 periods of minor RAS per year. The control group consisted of healthy individuals, and was matched in terms of age and sex with the case group.

The exclusion criteria for both case and control groups were as follows: any systemic disease; malnutrition; smoking; oral lesions other than RAS; the consumption of vitamin D and calcium supplements in the last 6 months; pregnancy; and lactating.

The participants were informed of the study design and provided written informed consent. Their medical history and clinical examination were recorded in the checklist.

Blood samples were collected by 1 laboratory technician from all participants in the laboratory of the Shahid Yahya Nejad hospital in Babol, Iran, during spring and summer (April-September). A total of $5 \mathrm{cc}$ of blood was drawn from each patient. Then, serum was separated from whole blood; it was centrifuged at 2,500 $\times \mathrm{g}$ for $10 \mathrm{~min}$ and was kept at $-80^{\circ} \mathrm{C}$ until the analysis was performed.

The measurement of vitamin D level was performed by means of the enzyme-linked immunosorbent assay (ELISA), using a laboratory kit (Cat. No. EUROIMMUN, EQ. 6411-9601; PerkinElmer, Lübeck, Germany) based on the present protocol of the kit.

All test steps were conducted using Elisys Uno, a fully automated ELISA analyzer (HUMAN, Wiesbaden, Germany).

According to serum vitamin D level, each participant was classified as 'normal' (30-50 ng/mL), 'insufficient' (20-30 ng/mL) or 'deficient' ( $<20 \mathrm{ng} / \mathrm{mL})$.

Finally, the data was analyzed with the independent samples $t$ test and the Mann-Whitney test, using the SPSS for Windows software, v. 17.0 (SPSS, Inc., Chicago, USA), with the significance level set at 0.05 .

\section{Results}

In this study, out of 86 individuals, 43 individuals (11 men and 32 women) were in the case group and 43 individuals ( 8 men and 35 women) were in the control group, and the 2 groups were matched in terms of sex $(p=0.600)$. 
The mean age was $32.56 \pm 7.93$ years in the case group and $33.74 \pm 7.07$ years in the control group, and there was no statistically significant difference between the groups in this respect $(p=0.460)$.

The mean serum level of vitamin D in the control group was $22.59 \pm 16.06 \mathrm{ng} / \mathrm{mL}$ and in the RAS patients, it was $13.89 \pm 8.19 \mathrm{ng} / \mathrm{mL}$. Vitamin D level in the control group was significantly higher than in the case group $(p=0.002)$ (Fig. 1).

Vitamin D categories in both groups are shown in Table 1. There was a statistically significant difference between the groups according to vitamin D categories $(p=0.032)$

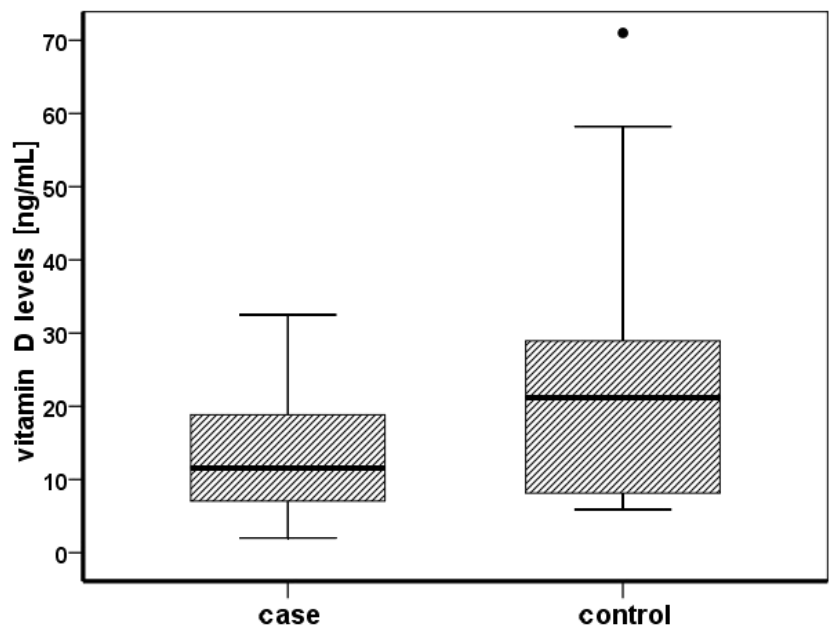

Fig. 1. Comparison of 25(OH)D concentrations between recurrent aphthous stomatitis (RAS) patients and the control group ( $p=0.002)$ Data presented as mean $(M) \pm$ standard deviation (SD).

Table 1. Vitamin D categories in the study groups

\begin{tabular}{|l|c|c|c|}
\hline \multicolumn{1}{|c|}{$25(\mathrm{OH}) \mathrm{D}$ category } & Case group & Control group & $p$-value \\
\hline Vitamin D-deficient & $32(74.4)$ & $21(48.8)$ & \\
Vitamin D-sufficient & $9(20.9)$ & $12(27.9)$ & $0.032^{*}$ \\
\hline Vitamin D-normal & $2(4.7)$ & $10(23.3)$ & \\
\hline
\end{tabular}

Data presented as number (percentage).

* statistically significant.

\section{Discussion}

In the present study, the serum levels of vitamin D in patients with minor RAS were lower than those in healthy individuals.

Few studies have evaluated the possible relationship between RAS and serum vitamin D level. In a study by Öztekin and Öztekin, ${ }^{10}$ similar to Bahramian et al.'s research, ${ }^{14}$ patients with RAS had vitamin D deficiency. According to Nalbantoğlu and Nalbantoğlu, the serum levels of vitamin D in children with RAS, aged 3-12 years, were decreased. ${ }^{15}$ The results of the above-mentioned studies are in line with our results, thus supporting the thesis that there is a relationship between vitamin D level and RAS.
On the contrary, Krawiecka et al. reported different results, implying no significant correlation between the serum level of vitamin D and RAS. ${ }^{7}$

The level of 25(OH)D was measured in all studies assessing serum vitamin $\mathrm{D}$.

It is well documented that $25(\mathrm{OH}) \mathrm{D}$ is the most appropriate marker to assess vitamin D status in humans. ${ }^{11}$ According to the confounding effect of age and sex on the serum level of vitamin D, matching for these 2 variables in both study groups decreases the bias; thus, in the current study, the effects of confounders were controlled.

The contradictory results obtained by Krawiecka et al. could be due to the lack of matching for sex. ${ }^{7}$

Lower serum levels of vitamin D in RAS patients as compared to the control group in Krawiecka et al.'s study might have been statistically significant if gender had been matched.

In this study, the mean serum level of $25(\mathrm{OH}) \mathrm{D}$ was 13.89 $\pm 8.19 \mathrm{ng} / \mathrm{mL}$ in the RAS group and $22.59 \pm 16.06 \mathrm{ng} / \mathrm{mL}$ in the control group, which was reported lower by Öztekin and Öztekin, ${ }^{10}$ and higher by Bahramian et al. ${ }^{14}$ and Nalbantoğlu and Nalbantoğlu. ${ }^{15}$

Although there are various methods to assess the serum levels of vitamin $\mathrm{D}$, including chemiluminescent immunoassay (CLIA), high-performance liquid chromatography (HPLC) and radioimmunoassay (RIA), there is no standard established. This variety of measuring methods may result in reporting different serum levels of vitamin D. ${ }^{16,17}$

In addition, differences in the measured serum level of vitamin D between the studies might be due to gender, age, geographical region, seasonal changes, diet, ethnicity, and culture. ${ }^{16,17}$

Vitamin D deficiency may be related to a higher melanin content in the skin and the use of extensive skin coverage. Hence in Middle East countries, including Iran, serum 25(OH)D levels are usually low. ${ }^{7,18,19}$

In the United States, $47 \%$ of African American infants and $56 \%$ of Caucasian infants have vitamin D deficiency, while in Iran, Turkey and India, over $90 \%$ of infants have vitamin D deficiency. ${ }^{19}$

Since RAS etiology is not clear and several factors are thought to contribute, there is no standard and definite treatment for it. Therapeutic options include local analgesics, corticosteroids and immune modulators, which are non-specific and administered based on the patient's symptoms..$^{10,20}$

Some studies have investigated the therapeutic role of various vitamins in treating aphthous stomatitis.

Lalla et al. showed that vitamin supplements (A, B1, B2, B3, B5, B6, B9, B12, C, D, and E) had no effect on the number and duration of aphthous lesions. ${ }^{20}$ However, Pederson et al. reported multivitamin to be effective in treating RAS, even when the serum levels of vitamin D were appropriate. ${ }^{21}$

A number of researchers suggested the role of innate and acquired immunity in the pathogenesis of RAS, which leads to the activation of neutrophils and the complement system, an increase in the number of NK cells and B lymphocytes, and an imbalanced $\mathrm{CD}^{+} / \mathrm{CD}^{+}$ratio. ${ }^{4,22,23}$ 
There are shreds of evidence supporting the regulatory role of vitamin D in the cellular and humoral immunity function. Most cells of the immune system, including APCs (e.g., macrophages, dendritic cells and T cells) express the hormone VDR. ${ }^{11,24}$

The biological effects of vitamin $\mathrm{D}$, including the regulation of innate and acquired immunity as well as its influence on the cytokine profile, imply the role of this hormone in RAS progression. ${ }^{11,24}$

A decrease in the serum level of vitamin D is reported in other autoimmune disorders, such as Behçet's disease, the periodic fever, aphthous stomatitis, pharyngitis, and cervical adenitis (PFAPA) syndrome, inflammatory bowel disease (IBD), rheumatoid arthritis, and autoimmune disorders of thyroid. ${ }^{7,8,10}$

\section{Limitations}

In the current study, the severity of aphthous lesions was not assessed. Therefore, further research with larger sample sizes is needed to investigate the intensity of aphthous lesions.

In addition, clinical trial studies to evaluate the potential therapeutic and protective role of vitamin D in RAS are warranted.

\section{Conclusions}

With our findings, the serum levels of vitamin D in patients with RAS were significantly lower than those in healthy individuals.

Given the regulatory effects of vitamin D on the immune system, and having considered the results of the current study, it can be concluded that low serum levels of vitamin D might be a probable etiologic factor for RAS, especially in genetically susceptible patients.

\section{ORCID iDs}

Masume Zakeri (1) https://orcid.org/0000-0001-7147-202X Hadi Parsian (1) https://orcid.org/0000-0002-3965-7566 Ali Bijani (1) https://orcid.org/0000-0003-2233-8726

Atena Shirzad (1) https://orcid.org/0000-0003-2235-2173

Nahid Neamati (1) https://orcid.org/0000-0001-8196-5813

\section{References}

1. Koybasi S, Parlak AH, Serin E, Yilmaz F, Serin D. Recurrent aphthous stomatitis: Investigation of possible etiologic factors. Am J Otolaryngol. 2006;27(4):229-232. doi:10.1016/j.amjoto.2005.09.022

2. Porter SR, Hegarty A, Kaliakatsou F, Hodgson TA, Scully C. Recurrent aphthous stomatitis. Clin Dermatol. 2000;18(5):569-578. doi:10.1016/s0738-081x(00)00147-4

3. Akintoye SO, Greenberg MS. Recurrent aphthous stomatitis. Dent Clin North Am. 2014;58(2):281-297. doi:10.1016/j.cden.2013.12.002

4. Ślebioda Z, Szponar E, Kowalska A. Etiopathogenesis of recurrent aphthous stomatitis and the role of immunologic aspects: Literature review. Arch Immunol Ther Exp (Warsz). 2014;62(3):205-215. doi:10.1007/s00005-013-0261-y
5. Khabbazi A, Ghorbanihaghjo A, Fanood F, Kolahi S, Hajialiloo M, Rashtchizadeh N. A comparative study of vitamin D serum levels in patients with recurrent aphthous stomatitis. Egypt Rheumatol. 2015;37(3):133-137. doi:10.1016/j.ejr.2014.07.005

6. Buño IJ, Huff JC, Weston WL, Cook DT, Brice SL. Elevated levels of interferon gamma, tumor necrosis factor alpha, interleukins 2, 4 , and 5 , but not interleukin 10, are present in recurrent aphthous stomatitis. Arch Dermatol. 1998;134(7):827-831. doi:10.1001/archderm.134.7.827

7. Krawiecka E, Ślebioda Z, Szponar E, Kowalska A, Dorocka-Bobkowska B. Vitamin D status in recurrent aphthous stomatitis. Postepy Dermatol Alergol. 2017;34(6):612-617. doi:10.5114/pdia.2017.69683

8. Kechichian E, Ezzedine K. Vitamin D and the skin: An update for dermatologists. Am J Clin Dermatol. 2017;19(1):223-235. doi:10.1007/ s40257-017-0323-8

9. Turhanoğlu AD, Güler H, Yönden Z, Aslan F, Mansuroglu A, Ozer C. The relationship between vitamin $D$ and disease activity and functional health status in rheumatoid arthritis. Rheumatol Int. 2011;31(7):911-914. doi:10.1007/s00296-010-1393-6

10. Öztekin A, Öztekin C. Vitamin D levels in patients with recurrent aphthous stomatitis. BMC Oral Health. 2018;18(1):186. doi:10.1186/ s12903-018-0653-9

11. Holick MF. Vitamin D: A millenium perspective. J Cell Biochem. 2003;88(2):296-307. doi:10.1002/jcb.10338

12. Prietl B, Treiber G, Pieber TR, Amrein K. Vitamin D and immune function. Nutrients. 2013;5(7):2502-2521. doi:10.3390/nu5072502

13. Nelson CD, Reinhardt TA, Beitz DC, Lippolis JD. In vivo activation of the intracrine vitamin $D$ pathway in innate immune cells and mammary tissue during a bacterial infection. PloS One. 2010;5(11):e15469. doi:10.1371/journal.pone.0015469

14. Bahramian A, Falsafi $P, A b b a s i ~ T$, et al. Comparing serum and salivary levels of vitamin $D$ in patients with recurrent aphthous stomatitis and healthy individuals. J Dent (Shiraz). 2018;19(4):295-300. PMCID:PMC6338692

15. Nalbantoğlu B, Nalbantoğlu A. Vitamin D levels in children with recurrent aphthous stomatitis. Ear Nose Throat J. 2019;99(7):460-463. doi:10.1177/0145561319882783

16. Kidd Man RE, Li LJ, Cheng CY, Wong TY, Lamoureux E, Sabanayagam $C$. Prevalence and determinants of suboptimal vitamin D levels in a multiethnic Asian population. Nutrients. 2017;9(3):313. doi:10.3390/nu9030313

17. Kagotho $E$, Omuse $G$, Okinda N, Ojwang P. Vitamin D status in healthy black African adults at a tertiary hospital in Nairobi, Kenya: A cross sectional study. BMC Endocr Disord. 2018;18:70. doi:10.1186/ s12902-018-0296-5

18. Lips P. Vitamin D status and nutrition in Europe and Asia. J Steroid Biochem Mol Biol. 2007;103(3-5):620-625. doi:10.1016/j.jsbmb.2006.12.076

19. Sizar O, Khare S, Goyal A, Bansal P, Givler A. Vitamin D deficiency. In: StatPearls [Internet]. Treasure Island, USA: StatPearls Publishing; 2021. NBK532266

20. Lalla RV, Choquette LE, Feinn RS, et al. Multivitamin therapy for recurrent aphthous stomatitis: A randomized, double-masked, placebo-controlled trial. J Am Dent Assoc. 2012;143(4):370-376. doi:10.14219/jada.archive.2012.0179

21. Pedersen A, Klausen B, Hougen HP, Ryder L, Winther K. Immunomodulation by LongoVital in patients with recurrent aphthous ulceration. J Oral Pathol Med. 1990;19(8):376-380. doi:10.1111/j.1600-0714.1990.tb00863.x

22. Bachtiar EW, Cornain S, Siregar B, Raharjo TW. Decreased CD4+/ CD8+ ratio in major type of recurrent aphthous ulcers: Comparing major to minor types of ulcers. Asian Pac J Allergy Immunol. 1998;16(2-3):75-79. PMID:9876944

23. Sistig S, Cekic-Arambasin A, Rabatic S, Vucicevic-Boras V, Kleinheinz J, Piffko J. Natural immunity in recurrent aphthous ulceration. J Oral PatholMed. 2001;30(5):275-280. doi:10.1034/j.1600-0714.2001.300504.x

24. Adorini L. Immunomodulatory effects of vitamin $D$ receptor ligands in autoimmune diseases. Int Immunopharmacol. 2002;2(7):1017-1028. doi:10.1016/s1567-5769(02)00049-8 